and the Reverend John Bachmann (1854), given by Harold Anderson.

- The History of Medicine and History of Nutrition Collections at Vanderbilt University Medical Center's Library have acquired Fasting Girls; Their Physiology and Pathology (1879), a scarce work on anorexia and the physiology of starvation written by William A. Hammond, M.D., surgeon-general of the Union Army, 1862-1864. A rare British cookbook by John Armstrong entitled, The Young Woman's Guide to Virtue, Economy and Happiness (1806) was also acquired. The 680-page household encyclopedia contains 200 pages of recipes, "rules for securing health," "rules of nursing and educating children," "a history of the work," "direction for writing letters," "memoirs of illustrious females," and a "history of women in different ages and countries."

\section{Grants \& gifts}

- The National Endowment for the Humanities (NEH) awarded nearly \$13.1 million in Challenge Grants to 26 educational and cultural institutions located in 15 states and the District of Columbia. Recipients of NEH challenge grants must generate three or sometimes four dollars for each dollar provided by the endowment. In all, nearly $\$ 40.6$ million in non-federal matching funds will be generated by the awards, bringing the total amount of support provided to $\$ 53.7$ million. Academic institutions receiving the challenge grants include:

- Amberst College received $\$ 500,000$ to support the renovation and expansion of the college's Robert Frost Library by providing space to accommodate a growing collection of books and manuscripts in the humanities, including a Center for Russian Culture. Plans proposed for the library project also include a new media center and an array of expanded reference technologies.

- Bard College, Annandale-on-Hudson, New York, received $\$ 500,000$ to support the construction and furnishing of a library addition and the creation of an endowment for library acquisitions in the humanities.

- DePaul University, Chicago, received $\$ 500,000$ to contribute to the construction of a new $\$ 25$ million library on its Lincoln Park Campus and to create an endowment fund to support acquisitions in the humanities. The challenge grant is the

(Cont. on page 130)

\title{
Media tips: How to get speaking opportunities
}

I think that talking to non-librarians about what we do is important and recently I learned more about how to do that. The presidents and vicepresidents of the ALA divisions received media training as part of the ALA World Book Award 1991-92. It was terrific! In the next several issues of CむRL News I'd like to share some of the very practical "how to" suggestions that were covered in the training, such as "Getting your message across" and "What to do when the media calls." I hope you will find them useful as you get messages about librarians out in your community.-Anne Beaubien, ACRL President

1. Be proactive. Don't wait for an invitation.

2. Identify potential audiences. Where do you need to speak to be sure that your message reaches the largest possible audience? Who needs to hear about librarians and library issues in order to take advantage of your services and, most importantly, support your campaign?

Reach out to diverse audiences--faculty and students, business and professional associations, legislators, parents, senior citizens, minorities, the economically disadvantaged, and physically challenged to name only a few. Remember to include gatherings of public policy officials, a city council or state legislative panel, newspaper editorial boards, local press clubs.

3. Make a list. Put together a mailing list with the names, addresses and telephone numbers of program officers for groups you wish to address. Your library may already have such a directory-if not, start one

4. Send a letter. Briefly explain what it is you wish to discuss, why the topic will bc of interest to their members and if there is any urgency involved.

"Physicians are dependent on the latest information to solve medical mysteries. Librarians work daily to ensure that information is available and affordable, but there are challenges to our ability to continue to ensure that access. I would appreciate an opportunity to explain to your members what is at risk and how we might work together to solve this looming problem."

5. Make follow-up calls. Personal contact can make the difference. Ask whether your letter was received, if there are questions. Is there another topic that would be of more interest to their members?

6. Do a great job and they'll ask you again, and recommend you to others. 